Document downloaded from:

http://hdl.handle.net/10251/103232

This paper must be cited as:

Pitarch, M.; Navarro-Peris, E.; Gonzálvez-Maciá, J.; Corberán, JM. (2017). Evaluation of different heat pump systems for sanitary hot water production using natural refrigerants. Applied Energy. 190:911-919. doi:10.1016/j.apenergy.2016.12.166

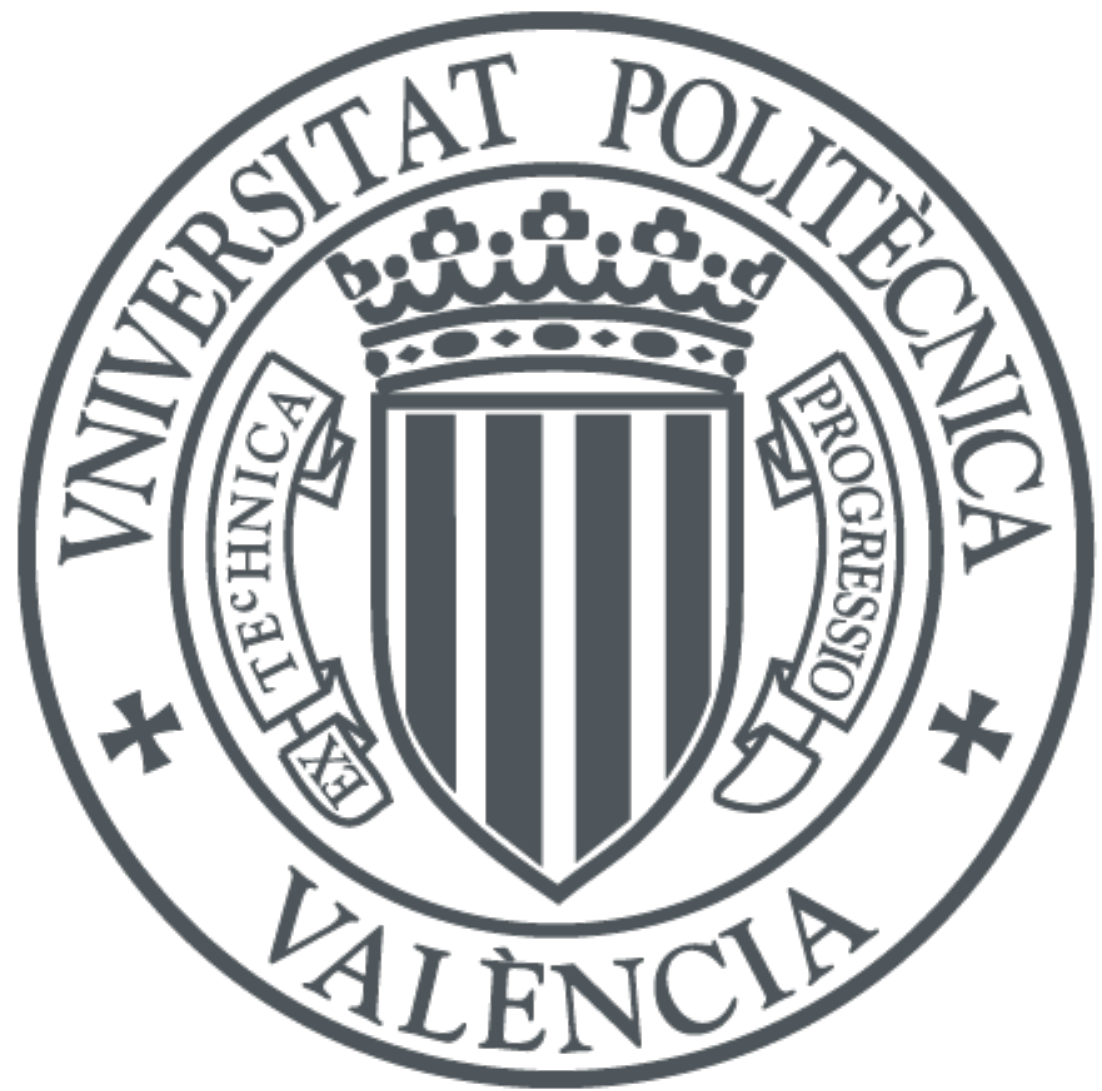

The final publication is available at

http://dx.doi.org/10.1016/j.apenergy.2016.12.166

Copyright Elsevier

Additional Information 


\title{
Evaluation of different heat pump systems for sanitary hot water production using natural refrigerants
}

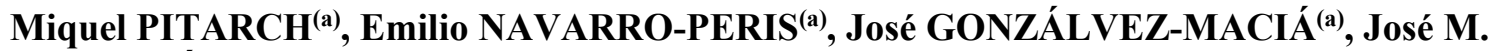 CORBERÁN ${ }^{(a)}$}

(a) Instituto de Ingeniería Energética, Universitat Politècnica de València, Camí de Vera s/n, Valencia, 46022, Spain

Tel: +34 963879123

enava@ter.upv.es

\begin{abstract}
Heat pumps that work with a high degree of subcooling in subcritical systems have shown a significant margin of improvement when working with sanitary hot water applications. Recently, two different approaches to overcome the high degree of subcooling have been presented in the literature: with a subcooler (separate from the condenser) and by making all the subcooling in the condenser. In this paper, a comparative evaluation between both alternatives is presented, and the obtained results are compared with a representative solution already available on the market using natural refrigerants for this application. The results of this analysis have shown that in a system with subcooling in the condenser, it is possible to obtain a COP comparable to that of transcritical $\mathrm{CO}_{2}$ heat pump water heaters. Furthermore, the system with subcooling has been demonstrated experimentally as being capable of producing water up to $90^{\circ} \mathrm{C}$ and has shown a COP up to $20 \%$ higher than some $\mathrm{CO}_{2}$ commercial products (catalogue data reference).
\end{abstract}

Keywords: propane, heat pumps, natural refrigerants, sanitary hot water, subcooling, energy recovery 


\section{NOMENCLATURE}

BPHE: Brazed plate heat exchanger

CFC: Chlorofluorocarbon

COP: Coefficient of performance [-]

EV: Expansion valve

GWP: Global warming potential

HCFC: Hydrochlorofluorocarbon

HFC: Hydrofluorocarbon

HP: Heat pump

ODP: Ozone depletion potential

Pc: Condensing pressure [bar]

Q: Capacity $[\mathrm{kW}]$

SHW: Sanitary hot water

SMC: Subcooling made in condenser

SMCL: Subcooling made in subcooler with larger condenser

SMS: Subcooling made in subcooler

SPF: Seasonal performance factor

$\mathrm{T}$ : Temperature $\left[{ }^{\circ} \mathrm{C}\right]$

Wc: Compressor power [kW]

\section{Subscripts}

cond: Condenser

disch: Discharge

h: Heating

sub: Subcooling

w: Water

w,ci: Water condenser inlet

w,co: Water condenser outlet

w,ei: Water evaporator inlet 


\section{INTRODUCTION}

An interesting, energy-efficient alternative to conventional sanitary hot water (SHW) systems (boilers), is the use of heat pump (HP) technologies, which is an application that has growing interest [1]. This potential for high efficiency is recognised by the European Directive 2009/28/CE [2], where a portion of the energy captured by a heat pump, having an estimated average seasonal performance factor (SPF) higher than a reference value, is considered as if it were obtained from renewable energy sources.

Since the first heat pump came up to market, engineers have been struggling to find a working fluid (refrigerant) that has to satisfy many requirements, such as thermodynamic, safety and environmental aspects. For instance, some fluorinated gases, such as CFCs and HCFCs have been (or will be soon) phased out [3]. HFCs do not contain chlorine or bromine, hence they are considered a negligible ODP, but are considered to be a greenhouse gas (high GWP), which has motivated counties to reduce HFC emissions [4]. On the other hand, natural refrigerants (carbon dioxide $-\mathrm{CO}_{2}$ (R744), hydrocarbons (HCs), and ammonia - NH3 (R717)) are pointed out as harmless to the ozone layer, with no influence on the greenhouse effect, or less so than traditional refrigerants, and with good thermodynamic properties [5].

The SHW application has a high water temperature lift, since the city water temperature is usually at $10^{\circ} \mathrm{C}$ and the supplied hot water is at least $60^{\circ} \mathrm{C}$. For these conditions, many researchers have drawn attention to the natural refrigerant, $\mathrm{CO}_{2}$, working in transcritical conditions as an efficient solution due to the high temperature glide in the refrigerant side. This effort has materialised in projects such as ECO-CUTE in Japan [6]. Works like [7-10] have shown the high efficiency of these cycles at water temperature lifts even higher than $50 \mathrm{~K}$. Pitarch et al. [11] compared, in a theoretical study, the COP penalty of different heat pump systems $\left(\mathrm{CO}_{2}\right.$ cycle with different subcritical refrigerants working at subcooling zero) for SHW production when the water temperature at the HP inlet increases (different water temperature lift). This study shows a higher COP for the $\mathrm{CO}_{2}$ cycle at high water temperature lift, but its performance has a high dependency with the water inlet temperature to the gas cooler. After a certain value of the inlet water temperature, the COP is higher for the subcritical systems. Transcritical cycles also heavily depend on the optimal control of cycle internal variables like the gas cooler pressure. In the last decade, several authors have studied the optimisation of such a system [12-14]. Although $\mathrm{CO}_{2}$ systems have an advantage in the SHW production because of the heat rejection in the 
transcritical region, they bring other problems at a high discharge pressure. Furthermore, it has a low critical temperature $\left(30.98^{\circ} \mathrm{C}\right)$, which makes it an unsuitable refrigerant to work in such applications where high evaporating temperatures can be reached [15], such as solar boosted or waste heat recovery heat pumps [16]. Subcritical systems (working with zero subcooling) have shown a lower performance for the high water temperature lift in SHW applications, but they have also been used for this purpose. This is the case for the commercial heat pump working with propane, Quantum [17], which warms up the water in sequences using low water temperatures lifts (around $5 \mathrm{~K}$ ), trying to increase the overall heating $\mathrm{COP}$ at the end of the process (warming water at typical temperatures of $60^{\circ} \mathrm{C}$ ).

The possible benefits of making subcooling have been a concern of many researchers in the last decade. For instance, Justo Alonso and Stene [18] compare the theoretical calculated COP of a $\mathrm{CO}_{2}$ transcritical cycle with two different systems working with propane; with and without a subcooler, $\mathrm{COP}$ is $20 \%$ higher when $\mathrm{CO}_{2}$ is used. Between the two propane cycles, they showed an increase of COP when working with a subcooler with respect to the one with no subcooling, although they do not mention the degree of subcooling.

For a given external conditions, subcooling depends on the active charge of the system (this charge does not include the charge contained in reservoirs like a liquid receiver). In this sense, some authors have indirectly studied the effect of moderate subcooling in the system performance for low temperature lift of the secondary fluid (not for the SHW application), as they studied the influence of charge on the heat pump performance in systems without a charge receiver [19-21]. Of those studies, is important to comment on Corberan et al. $[20,21]$, who studied the role of the charge in the system from a theoretical and experimental point of view; they pointed out that an optimum charge (and subcooling) exists for a given external condition.

For the case of a non-natural fluid, there are also works on SHW production, with no subcooling [22,23], and some concerning subcooling $[24,25,26,10]$. Cecchinato et al. [10] theoretically compare a $\mathrm{CO}_{2}$ transcritical cycle with R134a subcritical cycle working with subcooling. They pointed out that it is possible to increase the energy efficiency of the R134a cycle with an increase in subcooling. In this way, the results for SHW production are similar for both cycles in winter conditions, while $\mathrm{CO}_{2}$ has a higher performance in the summer. [26] studies the subcooling effect on an air conditioner system working with R410A. In that work, the subcooling was controlled with the expansion valve by placing a liquid receiver at the evaporator outlet. An optimal subcooling to maximise the COP was found. This optimum depends on the air inlet temperature to the 
condenser, but no information about the outlet temperature was reported. To the best of the authors' knowledge, there is no experimental study about the advantages of making subcooling in subcritical systems in order to profit from the high water temperature lift in the SHW application (around $50 \mathrm{~K}$ ). If a recommendation about subcooling is given, it is usually between $5 \mathrm{~K}$ and $10 \mathrm{~K}$.

In recent studies in the frame of the EU project NEXTHPG [27], a new heat pump design for SHW production were proposed, [28] evaluates theoretically the potential SPF of this system, Pitarch et al. [29] presented the experimental results of a propane water-to-water heat pump prototype for SHW production in the application of heat recovery from any water source, which is an application that has recently received considerable attention [30]. The prototype has produced high subcooling in order to profit from the high water temperature lift in the SHW application. The subcooling was made in a separate heat exchanger (subcooler). The results showed a significant improvement in performance compared with the propane cycle with 0 subcooling, especially in the high water temperature lift. In the nominal point, with a subcooling of $44 \mathrm{~K}$ and $50 \mathrm{~K}$ water temperature lift, the degree of improvement is $31 \%$. The COP in the nominal point was 5.61 , which is quite competitive with the $\mathrm{CO}_{2}$ systems for SHW production. In another study, Pitarch et al. [31] used a different heat pump design in order to produce subcooling. For this prototype, the control strategy used was entirely different because all of the subcooling was produced at the condenser. By means of an additional throttling valve, the active charge on the system can be controlled at any point, and thereby, the subcooling. The experimental results clearly showed an optimum subcooling (active charge) for each external condition (water temperatures). Unfortunately, a direct comparison between both alternatives could not be done, as the size of the condenser area was different for each heat pump.

From the results obtained in recent years, it can be concluded from the experimental point of view that propane is able to work at high performance in the SHW application if the system is able to work at high subcoolings. Nevertheless, no direct comparisons with the $\mathrm{CO}_{2}$ transcritical cycle-the direct competitor for the SHW application — have yet been made. Furthermore, it is claimed that $\mathrm{CO}_{2}$ is able to warm water up to $90^{\circ} \mathrm{C}$, while the propane cycle is usually tested warming water at $60^{\circ} \mathrm{C}$.

The present paper performs a global analysis of this type of system with the final aim of evaluating the real possibilities of implementing these heat pumps on the market. In order to do that, firstly, a fair comparison between the two HP designs presented by [29] and [31] is made. The comparison analyses the advantages of 
each proposed design, enumerating their advantages and disadvantages in such a way that a manufacturer could decide the preferred configuration according its criteria (price of the components, working conditions, control limitations, etc.). In order to do so, a model has been developed using the commercial software IMST-ART [32]. This model was validated with the experimental results from Pitarch et al. [31] (subcooling at the condenser); then the condenser of the model was increased to have the same heat exchange area as the HP design with a separate subcooler. Secondly, in previous works, these heat pumps were tested heating water up to $60^{\circ} \mathrm{C}$; in this work, a new experimental campaign was developed in order to evaluate the capabilities of this type of system to heat water up to $90^{\circ} \mathrm{C}$ with a significant water temperature lift. Finally, a direct comparison with the commercial $\mathrm{CO}_{2} \mathrm{HP}$ Q-ton [31], which has been considered as a representative, highly efficient alternative system in this paper, was made for all the working temperature ranges of this heat pump.

\section{HEAT PUMP DESIGNS}

The prototypes presented by [29] and [31] are water-to-water HPs for SHW production, in the application of heat recovery from any water source working with the natural refrigerant propane. In order to refer to each HP prototype, the following nomenclature will be used:

- SMS heat pump: The subcooling is made in a separate heat exchanger, the subcooler.

- $\quad$ SMC heat pump: The subcooling is made at the condenser (active charge control).

Both heat pump designs use the same evaporator, compressor and condenser, with the only difference being that in one case, a subcooler is connected in series with the condenser. The system was designed to obtain around $50 \mathrm{~kW}$ in the nominal point, i.e. $20^{\circ} \mathrm{C} / 15^{\circ} \mathrm{C}$ at the water inlet/outlet evaporator and producing sanitary hot water at $60^{\circ} \mathrm{C}$ from an inlet temperature of $10^{\circ} \mathrm{C}$.

\subsection{Refrigerant cycle: Subcooler in series with condenser (SMS heat pump)}

Figure 1 shows the scheme of the water-to-water heat pump prototype with a subcooler. A liquid receiver located right after the condenser ensures that (at steady state conditions) the refrigerant leaves the condenser in a liquid saturated state (point 3) and serves as a charge reservoir. For continuity, the refrigerant leaves the liquid receiver in saturated condition (at the condenser saturation temperature). Thereafter, the refrigerant is subcooled in a heat exchanger specifically designed for this reason (subcooler). At the water side, it passes first through the subcooler, where it is preheated before passing through the condenser, and where the water 
reaches the target temperature for the SHW application (usually $60^{\circ} \mathrm{C}$ ). The degree of subcooling will depend on the external conditions and the condenser size.

One should note that the refrigerant density of the subcooled refrigerant is higher than in the two-phase state. Thereby, if a separate heat exchanger is used to produce subcooling, the subcooler size can be optimised for the refrigerant liquid, so it has an appropriate refrigerant velocity for heat transfer. In this way, the subcooler requires a smaller plate pitch than at the condenser.

a)

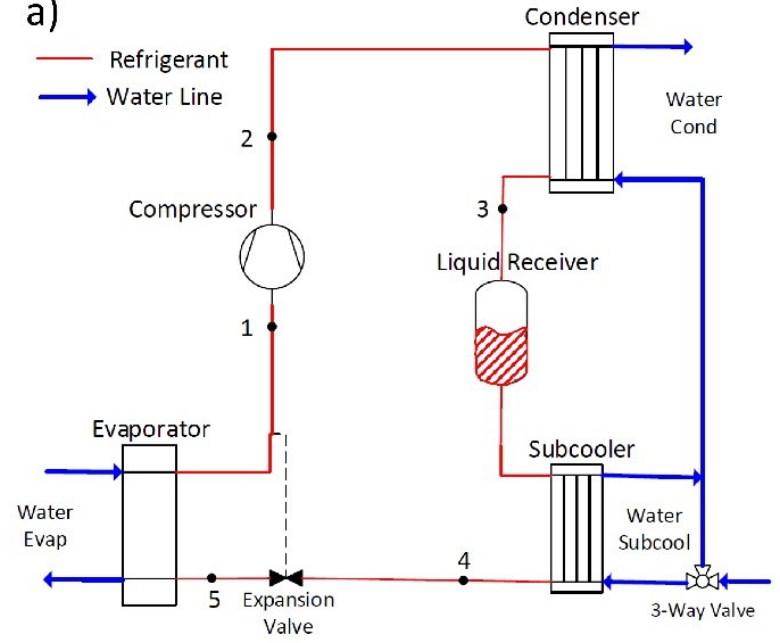

b)

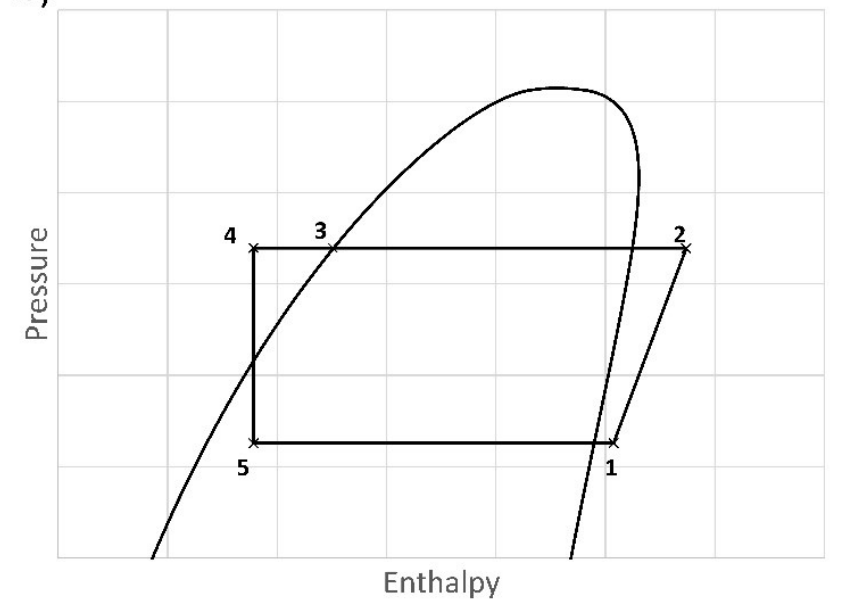

Figure 1: Heat Pump subcooler in series with condenser; a) scheme, b) P-h diagram.

\subsection{Refrigerant cycle: Subcooling made in the condenser (SMC heat pump)}

Figure 2 shows the scheme of the water-to-water heat pump to make subcooling in the condenser. The evaporator, compressor, condenser and liquid receiver are the same as in the previous case, but for this case, the subcooler has been removed from the system. A throttling valve is located between the condenser and the liquid receiver, which introduces an active control of refrigerant charge in the system; hence, it can be used to set the subcooling at the condenser independently from the external conditions. In a system with a fixed area for heat exchange in the high pressure side, this feature allows the condenser to dedicate the optimum needed area for subcooling at each condition, while the SMS system has a fixed heat exchange area for subcooling. Liquid receivers are normally charge reservoirs used as passive elements to accommodate the changes in the active refrigerant charge due to changes in the operating mode or changes in the external conditions. In this 
case, the main function will be to accommodate the changes in the active charge due to variations in the degree of subcooling at the condenser and to assure saturated liquid conditions at the outlet of the throttling valve. The pressure at the inlet of the throttling valve (point 3) will depend on the heat transfer process at the condenser, and the pressure at the liquid receiver (point 4) will depend on the opening of the throttling valve and correspond to the one for the saturated liquid with the same enthalpy of the liquid exiting the condenser. The liquid receiver ensures that the refrigerant leaves the throttling valve in a liquid saturated state (point 4), which corresponds to the saturation temperature at the liquid receiver pressure. Therefore, since the throttling valve outlet is constrained to be on the saturation liquid line, the refrigerant at the condenser outlet (point 3) must be subcooled. The pressure drop at the throttling valve will determine the subcooling produced at the condenser. By increasing the pressure drop at the throttling valve, the refrigerant charge migrates from the liquid receiver to the condenser, which is flooded with refrigerant liquid, producing more subcooling.

With this configuration, there is almost an independent control of the subcooling and the superheat at the compressor inlet. The throttling valve controls the subcooling, and only a slight variation of the condensing pressure is produced in the working range of the system. The expansion valve controls the superheat at the compressor inlet.

a)

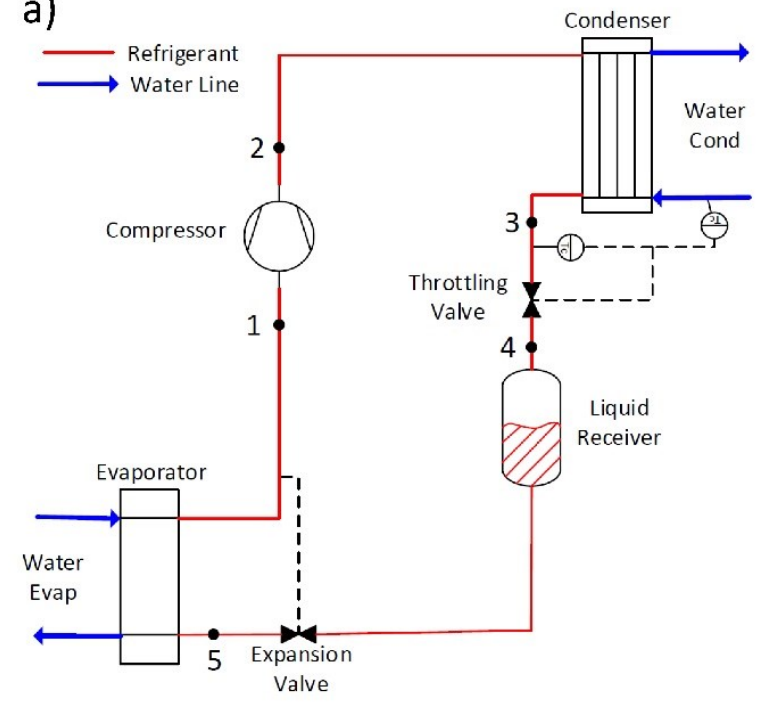

b)

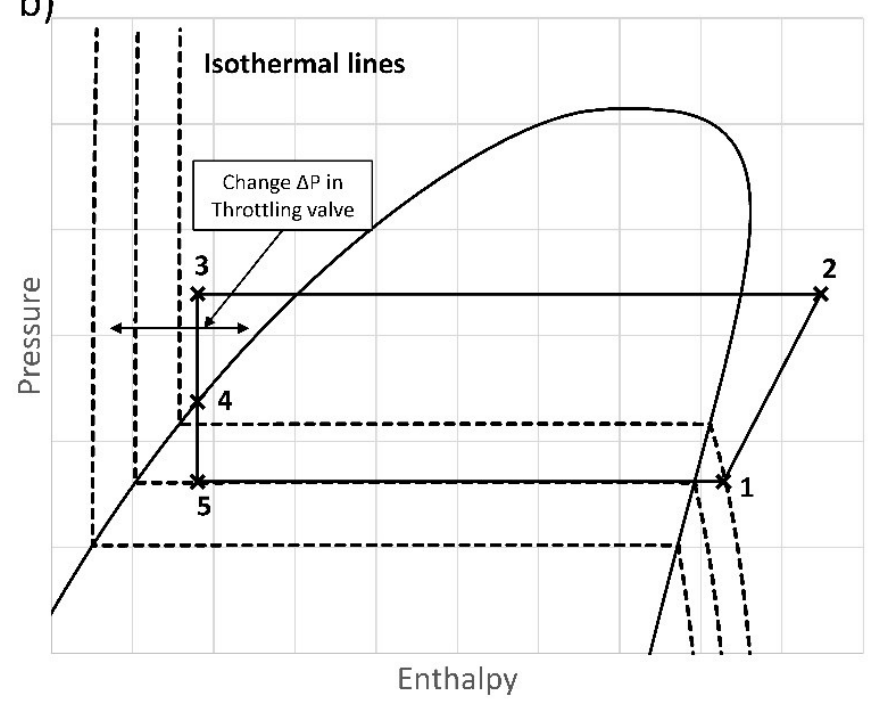

Figure 2: Heat Pump subcooling controlled by a throttling valve; a) scheme, b) P-h diagram.

\section{MODEL}


To predict the heat pump performance, the commercial IMST-ART software has been used [30]. This is dedicated software for modelling heat pump systems as a whole, according to the state-of-the-art. For more detailed description of the model see [34].

The model incorporates a number of sub-models representing the different parts of the heat pump: compressor, condenser, evaporator and expansion valve. The definition of the heat exchangers is based on their geometric characteristics and for compressors, the available information supplied by manufacturers. The expansion valve is modelled as an isenthalpic pressure drop in order to fulfil the desired superheat - in this case $10 \mathrm{~K}$. The throttling valve cannot be modelled, but the subcooling can be introduced as a parameter, so in practice, the HP subcooling in the condenser can be modelled with the IMST-ART software.

Table 1 shows the main components of both systems.

\begin{tabular}{lcc}
\hline \multicolumn{1}{c}{ Component } & Type & Size \\
\hline Compressor & Scroll (2900 rpm) & $29.6 \mathrm{~m}^{3} \mathrm{~h}^{-1}$ \\
Condenser & BPHE Counterflow & $3.5 \mathrm{~m}^{2}$ \\
Subcooler & BPHE Counterflow & $0.87 \mathrm{~m}^{2}$ \\
Evaporator & BPHE Counterflow & $6 \mathrm{~m}^{2}$ \\
Liquid Receiver & - & 71 \\
Expansion Valve & Electronic EV & $5-60 \mathrm{~kW}$ \\
Throttling Valve & Electronic EV & $5-60 \mathrm{~kW}$ \\
\hline
\end{tabular}

Table1: Components of the HP system.

The heating COP calculation does not take into account the consumption of the auxiliary components unless it is indicated. In calculations where the auxiliary consumption has been taken into account, the heating COP is calculated according to the European standard 14511-3, and these calculations include the consumption of the water pumps.

\subsection{Model validation: Subcooling made in the condenser (SMC)}

For the validation of the SMC heat pump model, the experimental results from Pitarch et al. [31] have been used. Figure 3 shows this comparison for COP and condensation pressure. The results are presented as a function of the subcooling and for different water inlet temperatures for the condenser $\left(\mathrm{T}_{\mathrm{w}, \mathrm{ci}}\right)$. The inlet water 
temperature for the evaporator $\left(\mathrm{T}_{\mathrm{w}, \mathrm{i}}\right)$ is fixed to $20^{\circ} \mathrm{C}$ and the water mass flow rate for the evaporator is fixed to $7000 \mathrm{kgh}^{-1}$. These are the evaporator conditions except when different values are specifically indicated.

There is good agreement between the experimental and theoretical values for the COP; COP dependency with the subcooling is captured by the model. The COP increases with subcooling up to a maximum, and then decreases. The optimum subcooling is reproduced with a deviation lower than $2 \mathrm{~K}$. The maximum discrepancies are found at high water inlet temperatures to the condenser $\left(\mathrm{T}_{\mathrm{w}, \mathrm{c}}=50^{\circ} \mathrm{C}\right)$, being less than $4 \%$.

Regarding the condensing pressure, the theoretical results also match the experimental results. At low subcooling, the condensing pressure increases slowly with subcooling, and after a certain value of the subcooling, it starts to increase at a higher rate. This point of inflection is where the maximum COP takes place. As in the heating COP, the greatest discrepancies are found at high water inlet temperatures to the condenser $\left(\mathrm{T}_{\mathrm{w}, \mathrm{c}}=50^{\circ} \mathrm{C}\right)$, being less than $2 \%$.

Table 2 shows the heating COP, the heating capacity and the compressor consumption for the model as well as the experimental values working at the optimum subcooling. Great agreement for the three variables can be seen. COP discrepancies are below $1 \%$ for $\mathrm{T}_{\mathrm{w}, \mathrm{ci}} 10^{\circ} \mathrm{C}$ and $30^{\circ} \mathrm{C}$, while the heating capacity and the compressor consumption are all below $2 \%$ of discrepancies.
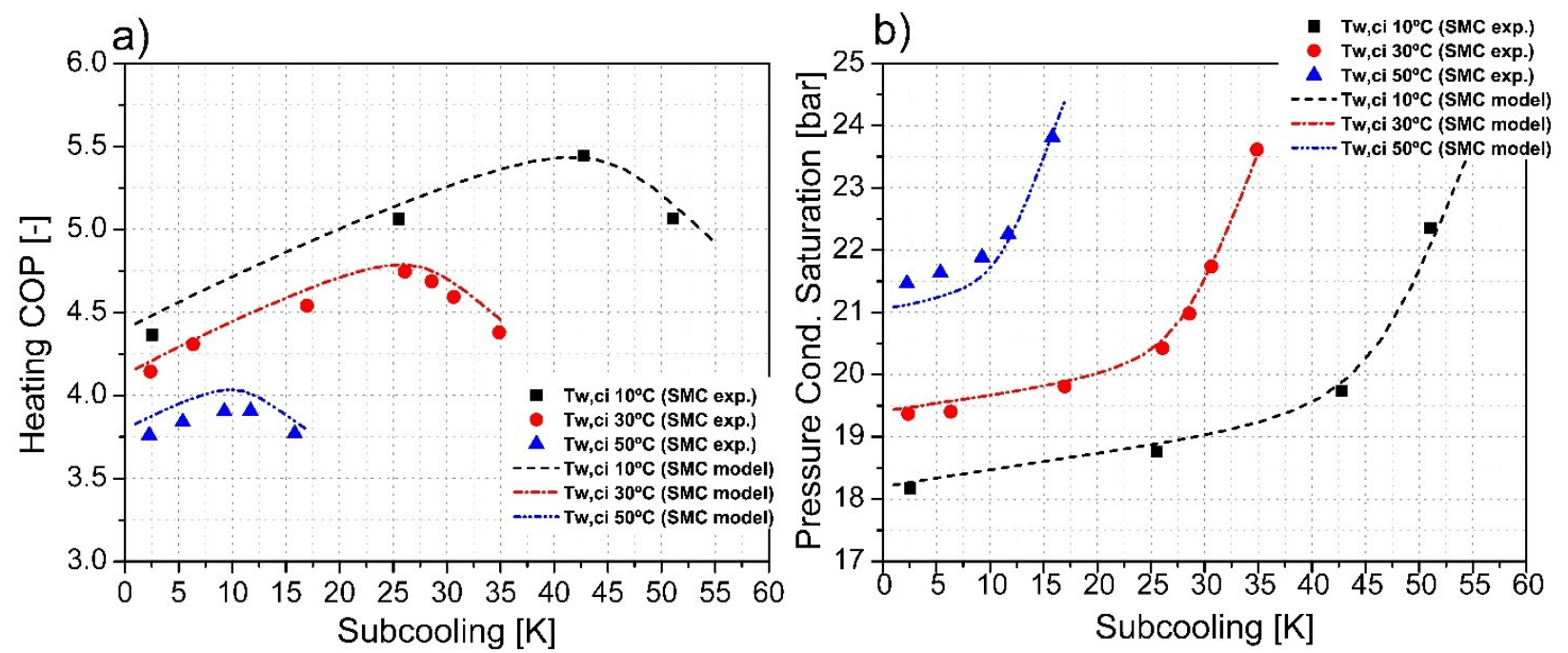

Figure 3: Model validation; a) heating COP, b) condensing pressure.

\begin{tabular}{lcccccc}
\hline & $\begin{array}{c}\text { COP }_{h} \\
\text { SMC exp. }\end{array}$ & $\begin{array}{c}\mathrm{Q}_{h}[k W] \\
\text { SMC exp. }\end{array}$ & $\begin{array}{c}\text { Wc }[k W] \\
\text { SMC exp. }\end{array}$ & $\begin{array}{c}\text { COP }_{h} \\
\text { SMC model }\end{array}$ & $\begin{array}{c}\mathrm{Q}_{h}[k W] \\
\text { SMC model }\end{array}$ & $\begin{array}{c}\text { Wc }[k W] \\
\text { SMC model }\end{array}$ \\
\hline Tw,ci = 10C & 5.44 & 46.31 & 8.51 & 5.43 & 45.57 & 8.39 \\
Tw,ci = 30.C & 4.75 & 40.98 & 8.64 & 4.79 & 41.55 & 8.68 \\
Tw,ci = 50C & 3.91 & 35.96 & 9.21 & 4.03 & 36.54 & 9.06 \\
\hline
\end{tabular}

Table 2: SMC mode validation at the optimum subcooling. 


\subsection{Model adjustment to the heat pump with subcooler}

Comparing the experimental results obtained by Pitarch et al. [29] and [31], the SMS heat pump configuration (with subcooler) has a slightly higher performance than the SMC heat pump configuration (subcooling at condenser). For instance, at the nominal point $\left(\mathrm{T}_{\mathrm{w}, \mathrm{e}}=20^{\circ} \mathrm{C}\right.$ and warming water from $10^{\circ} \mathrm{C}$ to $\left.60^{\circ} \mathrm{C}\right)$, the SMS heat pump gave a heating COP of 5.61, while the COP for SMC was 5.35.

Nevertheless, the experimental results obtained with the separate subcooler configuration cannot be fairly compared with the SMC heat pump configuration, since the first one has a $25 \%$ greater heat exchange area on the high pressure side.

To make a fair comparison between both systems, the condenser of the SMC model has been enlarged in order to have the same heat exchange area as the condenser and the subcooler of the SMS HP prototype together. In this sense, the results of both systems can be compared directly.

In order to have an equal heat transfer area in the high pressure side without significantly changing the heat transfer coefficient, the height of the condenser was increased. The other alternative, increasing the number of plates, affects the refrigerant velocity, and hence, the heat transfer coefficient. Therefore, the condenser height will go from $0.476 \mathrm{~m}$ to $0.591 \mathrm{~m}$, which is $25 \%$ longer ( $25 \%$ more area). The area of the modified condenser will be $4.37 \mathrm{~m}^{2}$, which is the same as the condenser and the subcooler together. For the sake of clarity, the SMC model with the enlarged condenser will be referenced as SMCL (the subcooling made in subcooler with larger condenser). One should note that although the subcooler area has been added to the condenser, the plate pitch of the heat exchange area dedicated to the subcooling in the SMS system is different from the SMCL system.

\section{RESULTS}

\subsection{High efficient subcritical heat pump alternatives to produce SHW}

Figure 4a shows the heating COP as a function of the subcooling for the SMC and SMCL models (different condenser height) and the experimental results for the SMS heat pump configuration. The COP increased for the whole range of subcoolings for the SMCL model (condenser height $0.59 \mathrm{~m}$ ). At low and high subcooling, the COP improvement is moderate. For instance, in the case of $\mathrm{T}_{\mathrm{w}, \mathrm{c}}=50^{\circ} \mathrm{C}$ at subcooling higher than $12 \mathrm{~K}$, the 
$\mathrm{COP}$ is practically the same for both condenser heights. The maximum COP improvement is found at the optimum subcooling.

As reported by Pitarch et al. [31], when the SMS configuration is compared with the SMC with a smaller heat exchange area, the SMS system has a greater performance. This situation changes if the system is equipped with a larger condenser with a heat exchange area equivalent to the SMS (the SMCL model). In this case, the performance of SMCL is still below the results for SMS at $\mathrm{T}_{\mathrm{w}, \mathrm{ci}}=10^{\circ} \mathrm{C}$, but at higher $\mathrm{T}_{\mathrm{w}, \mathrm{ci}}$, SMCL has a higher performance than the SMS for water inlet temperatures of $30^{\circ} \mathrm{C}$ and $50^{\circ} \mathrm{C}$.

Figure $4 \mathrm{~b}$ shows the condensing pressure as a function of the subcooling. The condensing pressure is reduced for the whole subcooling range of the enlarged condenser model (SMCL). This decrease is more significant at the optimum and low subcooling. At $\mathrm{T}_{\mathrm{w}, \mathrm{c}}=50^{\circ} \mathrm{C}$, the condensing pressure at the optimum subcooling decreased below the corresponding experimental pressure for the SMS HP design. At lower $\mathrm{T}_{\mathrm{w}, \mathrm{ci}}\left(30^{\circ} \mathrm{C}\right.$ and $\left.10^{\circ} \mathrm{C}\right)$, the condensing pressure at the optimum subcooling is still higher than the corresponding experimental pressure for the SMS heat pump design.

Table 3 shows the heating COP, the heating capacity $\left(\mathrm{Q}_{\mathrm{h}}\right)$, the heat corresponding to the subcooling $\left(\mathrm{Q}_{\text {sub }}\right)$, the heat corresponding to condensing + de-superheat $\left(\mathrm{Q}_{\mathrm{cond}}\right)$ and the compressor consumption. These parameters are shown for the SMS heat pump prototype (experimental) and the results for the SMCL model (height of $0.59 \mathrm{~m}$ ) working at optimum subcooling. The heating capacity is slightly higher for the SMCL model, while the compressor consumption depends on the point.
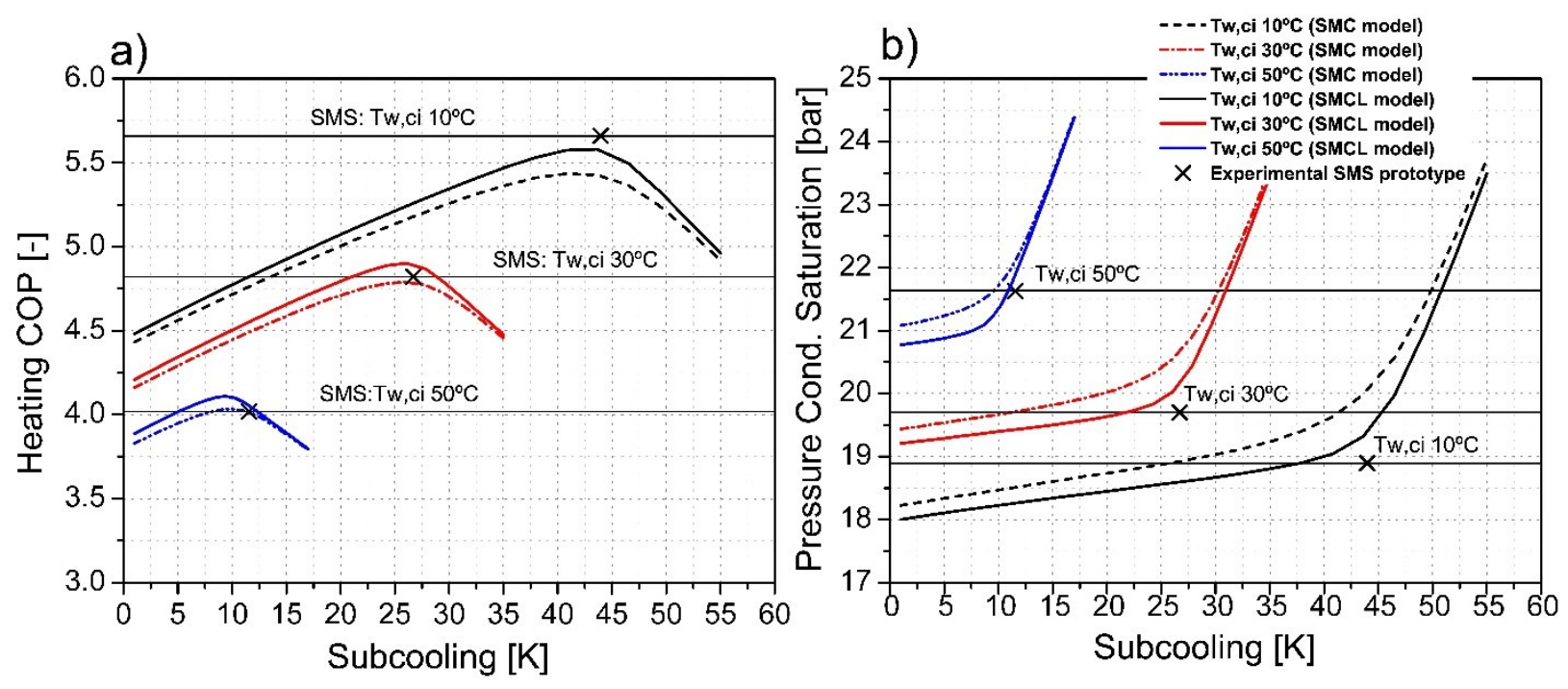

Figure 4: Results for two condenser height; a) heating COP, b) condensing pressure. 


\begin{tabular}{|c|c|c|c|c|c|c|c|c|c|c|}
\hline & $\mathrm{COP}_{\mathrm{h}}$ & $\begin{array}{c}\mathrm{Q}_{\mathrm{h}} \\
{[\mathrm{kW}]}\end{array}$ & $\begin{array}{c}Q_{\text {sub }} \\
{[\mathrm{kW}]}\end{array}$ & $\begin{array}{l}Q_{\text {cond }} \\
{[\mathrm{kW}]}\end{array}$ & $\begin{array}{l}\text { Wc } \\
{[k W]}\end{array}$ & $\begin{array}{l}\mathrm{COP}_{\mathrm{h}} \\
\text { Model }\end{array}$ & $\begin{array}{c}Q_{h, S M C L} \\
{[k W]}\end{array}$ & $\begin{array}{c}Q_{\text {sub,SMCL }} \\
{[\mathrm{kW}]}\end{array}$ & $\begin{array}{c}Q_{\text {cond,SMCL }} \\
{[\mathrm{kW}]}\end{array}$ & $\begin{array}{c}\mathrm{Wc}_{\mathrm{SMCL}} \\
{[\mathrm{kW}]}\end{array}$ \\
\hline$T w, c i=10 \circ C$ & 5.66 & 45.72 & 12.07 & 33.65 & 8.08 & 5.58 & 46.15 & 12.47 & 33.68 & 8.26 \\
\hline $\mathrm{Tw}, \mathrm{ci}=30 \circ \mathrm{C}$ & 4.82 & 40.07 & 7.30 & 32.77 & 8.31 & 4.91 & 41.76 & 8.03 & 33.73 & 8.52 \\
\hline$T w, c i=50 \cong C$ & 4.00 & 35.95 & 3.26 & 32.68 & 8.98 & 4.11 & 36.53 & 3.15 & 33.38 & 8.89 \\
\hline
\end{tabular}

Table 3: Experimental SMS and SMCL model comparison at optimum subcooling.

Figure 5 shows the condenser area dedicated for subcooling as a function of subcooling for different water inlet temperatures to the condenser $\left(\mathrm{T}_{\mathrm{w}, \mathrm{ci}}\right)$ for the SMCL and the fixed area for the SMS. The used area per subcooling degree depends strongly on the $\mathrm{T}_{\mathrm{w}, \mathrm{c} \text {. }}$. For instance, the dedicated area to produce $15 \mathrm{~K}$ of subcooling goes from $5 \%$ to $65 \%$ for $\mathrm{T}_{\mathrm{w}, \mathrm{ci}}=10^{\circ} \mathrm{C}$ and $\mathrm{T}_{\mathrm{w}, \mathrm{ci}}=50^{\circ} \mathrm{C}$, respectively. Nevertheless, when the system works at optimal subcooling, the area dedicated to subcooling is lower as $\mathrm{T}_{\mathrm{w}, \mathrm{c}}$ increases. The dedicated area at optimum subcooling for $\mathrm{T}_{\mathrm{w}, \mathrm{c} i}=10^{\circ} \mathrm{C}$ is $47 \%$, while it is $24 \%$ when $\mathrm{T}_{\mathrm{w}, \mathrm{c}}=50^{\circ} \mathrm{C}$. This might explain why the performance of SMCL compared with the SMS system improves at higher $\mathrm{T}_{\mathrm{w}, \mathrm{ci}}$. At some points, the subcooling area for the SMC system could be oversized and it would be better to use that heat exchange area in the condenser, while the subcooling area at the SMCL system is optimised at any point.

Nevertheless, when comparing the area dedicated for subcooling in the SMS and SMCL systems, it can be seen that in all the cases, the area dedicated for subcooling in the SMS system is smaller than in the SMCL system. This point is related to the fact that the subcooler of the SMS system has been designed specifically to subcool the refrigerant. Hence, the plate pitch of that heat exchanger is thinner in a condenser and allows a higher heat transfer coefficient of the liquid refrigerant and, therefore, a smaller area is required. 


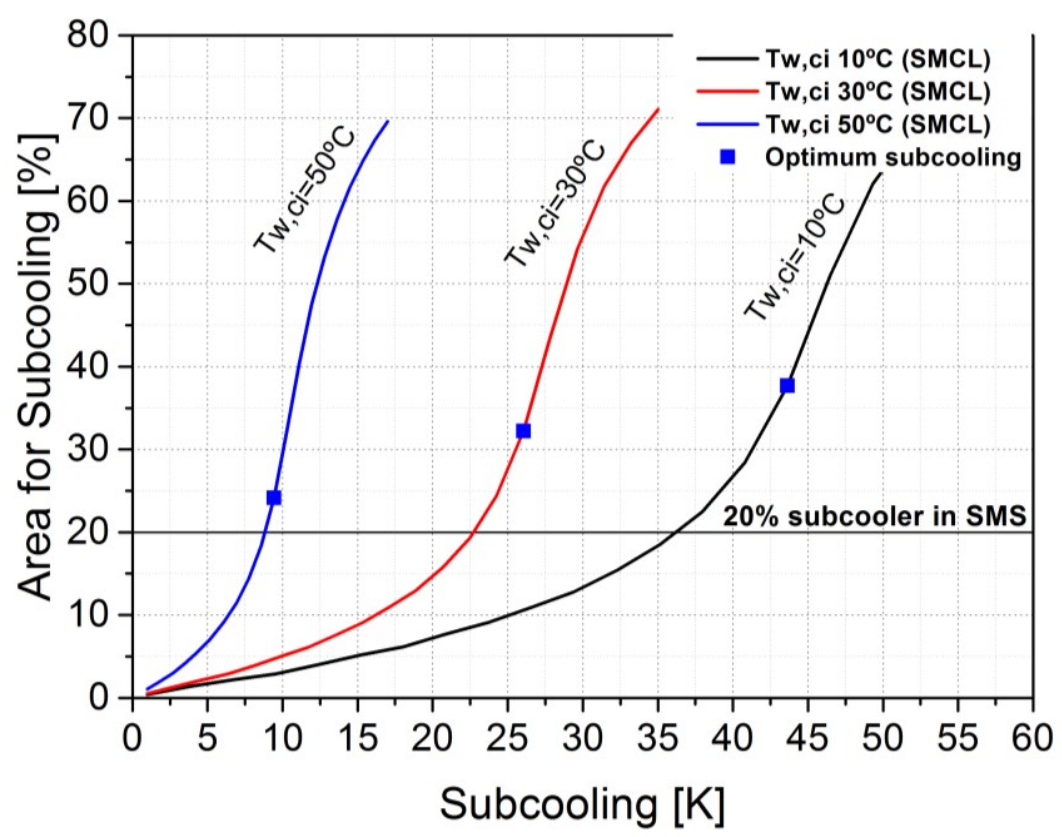

Figure 5: \% of area dedicated for subcooling as a function of subcooling and $\mathrm{T}_{\mathrm{w}, \mathrm{ci}}$ (SMCL and the fixed area for SMS).

Figure 6 shows the heating COP and the condensing pressure as a function of subcooling and the condenser size (height). The inlet and outlet water temperature to the condenser are fixed at $30^{\circ} \mathrm{C}$ and $60^{\circ} \mathrm{C}$, respectively. For a constant condenser size, the COP increases with subcooling up to a maximum value. The optimum subcooling is around $25 \mathrm{~K}$ for all condenser sizes and for the selected temperature lift. Condenser size has different trends depending on the degree of subcooling:

1) At low subcoolings, the COP increases slightly with the condenser size and beyond a defined size, but the increase is almost insignificant.

2) At the optimum subcooling, the COP increases significantly with the condenser size, and the increase is maintained for the whole size range studied. The degree of improvement is higher at smaller sizes.

3) At high subcoolings, the COP increases with a small condenser size, but after a certain point, condenser size has no effect on the COP.

Regarding the condensing pressure, it decreases with the condenser size for low and optimal subcooling, but at high subcooling, the condensing pressure has almost no dependence in condenser size. 
a)

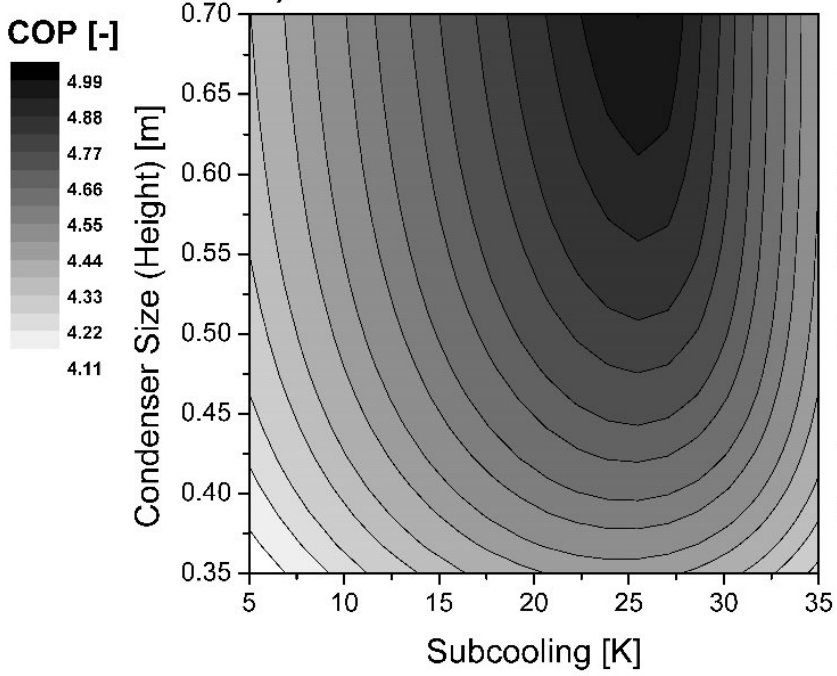

b)

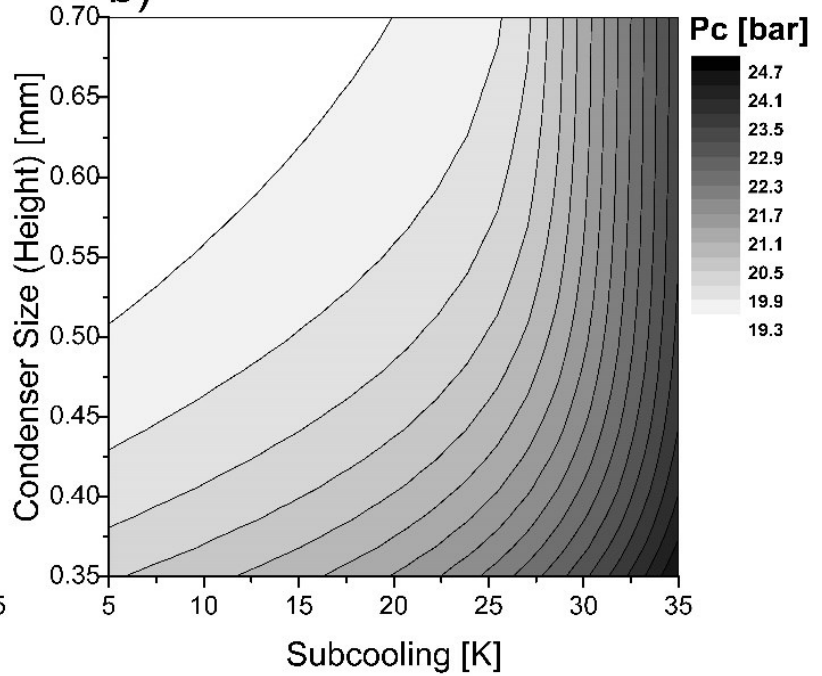

Figure 6: a) Heating COP and b) condensing pressure as a function of subcooling and condenser size $\left(\mathrm{T}_{\mathrm{w}, \mathrm{ci}}=30^{\circ} \mathrm{C}\right)$.

Figure 7a shows the condenser dedicated area as a function of condenser size for de-superheat, two-phase and subcooling. The dedicated area for de-superheat and subcooling decreases slightly with condenser size, by about $2 \%$ when going from a condenser height of $0.35 \mathrm{~m}$ to $0.7 \mathrm{~m}$. On the other hand, the dedicated area for the two-phase flow increases by $4 \%$. The percentage of the dedicated area for subcooling decreases with size, although the total area increases. Figure $7 \mathrm{~b}$ shows the refrigerant and water temperature profile in the condenser for two different condenser sizes, $0.35 \mathrm{~m}$ and $0.70 \mathrm{~m}$. A better temperature match between the refrigerant and water at the bigger condenser can be seen.
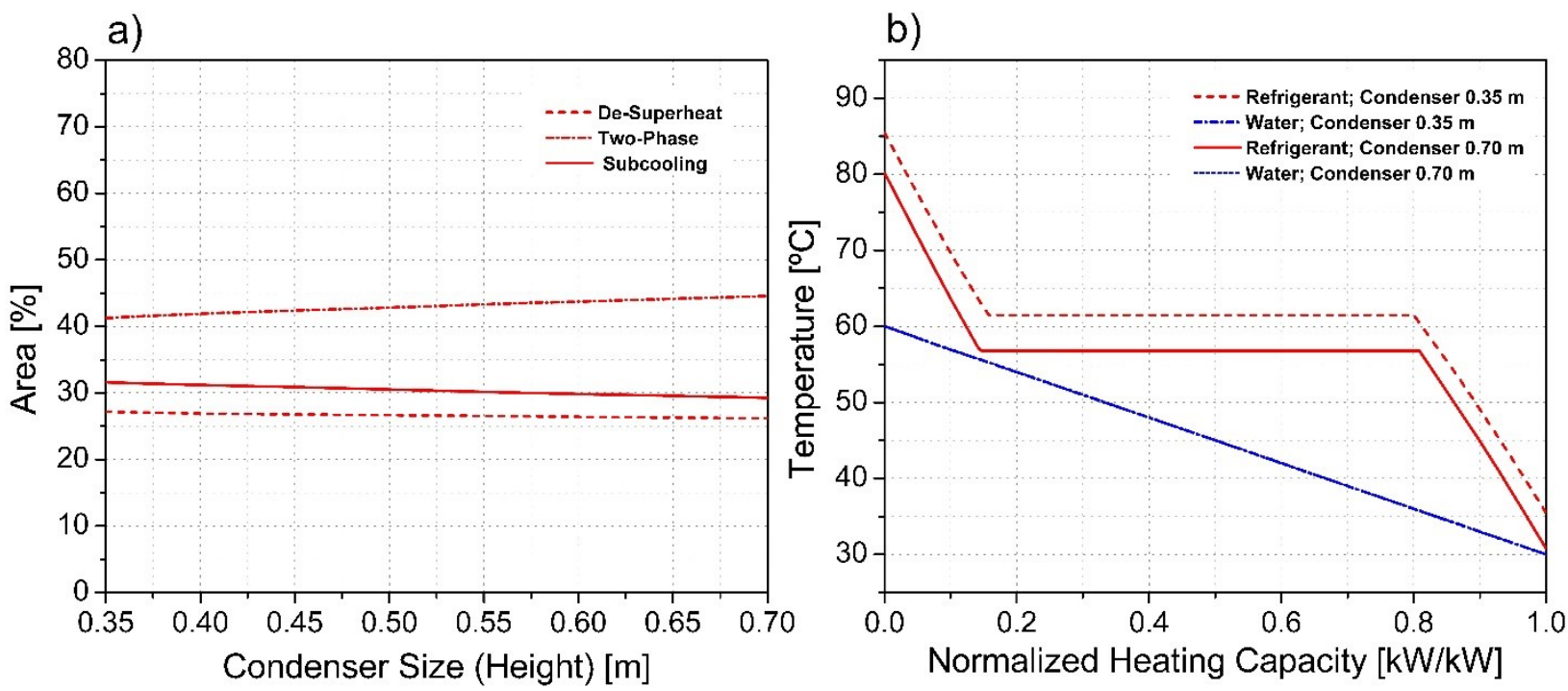

Figure 7: a) Condenser dedicated area as a function of condenser size, b) refrigerant and water temperature profile in the condenser $\left(\mathrm{T}_{\mathrm{w}, \mathrm{ci}}=30^{\circ} \mathrm{C}\right)$. 
From all these results, it can be concluded that, depending on the working conditions, the SMC design could obtain a better performance than the SMS due to the ability to adjust the area dedicated for subcooling at any point. Nevertheless, the SMC design has other disadvantages that need to be considered. SMC is not able to work at the optimum condition when the refrigerant outlet temperature at the condenser $\left(\mathrm{T}_{\mathrm{w}, \mathrm{i}}\right)$ is lower than the evaporating temperature, for instance, at the point $\mathrm{T}_{\mathrm{w}, \mathrm{ci}}=10^{\circ} \mathrm{C}$ and $\mathrm{T}_{\mathrm{w}, \mathrm{i}}=30^{\circ} \mathrm{C}$. The refrigerant temperature at the condenser outlet is limited by $\mathrm{T}_{\mathrm{w}, \mathrm{ci}}$, which is the maximum possible evaporating temperature ( 0 bar pressure drop at the EV). Therefore, at this point, the maximum evaporating pressure is lower than the corresponding one at $\mathrm{T}_{\mathrm{w}, \mathrm{e}}=30^{\circ} \mathrm{C}$, leading to lower performance than expected by the boundary conditions.

Figure 8 shows this behaviour in the experimental values from Pitarch et al. [31], where the COP starts to decrease after $36 \mathrm{~K}$ of subcooling. This effect is not taken into account in the SMC model, which has the optimum COP at $43 \mathrm{~K}$ of subcooling. For the case of the SMS design, the refrigerant temperature at the subcooler outlet does not determine the evaporating temperature, since the refrigerant can enter the evaporator in subcooled conditions, and the evaporating pressure is not limited (see Pitarch et al. [29]). The SMS design does not have this limitation, and in the case of working at high evaporating temperatures and high subcooling, could be considered a better design.

There are several techniques to avoid the behaviour described above. The high water temperatures at the evaporator inlet could be used directly to pre-heat up the water before entering at the condenser. In this way, the subcooling operation of the system is reduced and the water temperature at the inlet of the evaporator is reduced. Another possibility, shown in Lihan [26], is to place the liquid receiver at the evaporator outlet and to control the subcooling directly with the expansion valve. In this way, the evaporating pressure would not be limited by the refrigerant temperature at the condenser outlet. 


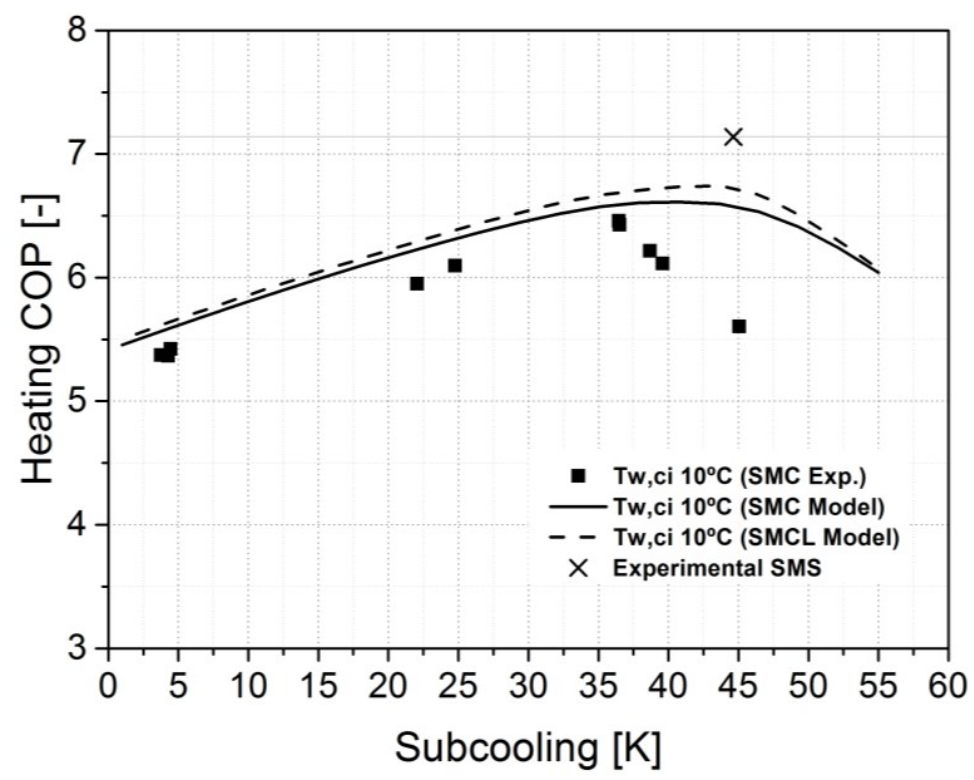

Figure 8: Heating COP as a function of subcooling for $\mathrm{T}_{\mathrm{w}, \mathrm{e}}=30^{\circ} \mathrm{C}$ and $\mathrm{T}_{\mathrm{w}, \mathrm{c}}=10^{\circ} \mathrm{C}$.

\subsection{Comparison $\mathrm{R290}$ and the reference $\mathrm{CO}_{2}$ heat pump for $\mathrm{SHW}$}

Both highly efficient subcritical heat pump configurations have been analysed, thus, a comparison of these results with other high efficient alternatives available on the market has been done.

Figure 9 shows the heating COP as a function of the water inlet temperature to the condenser $\left(\mathrm{T}_{\mathrm{w}, \mathrm{i}}\right)$ and producing hot water at $60^{\circ} \mathrm{C}$. The figure compares the experimental results for the SMS HP, the SMCL model (condenser of $0.59 \mathrm{~m}$ working at the optimum subcooling) and the commercial, high-efficiency HP for sanitary hot water production, Q-ton. The reference $\mathrm{CO}_{2} \mathrm{HP}$ is an air-to-water $\mathrm{CO}_{2}$ heat pump working in transcritical conditions. Since the secondary fluid at the evaporator is different for the propane and the $\mathrm{CO}_{2} \mathrm{HPs}$, different temperatures have been chosen for each cycle in order to compare them fairly: an air ambient temperature of $25^{\circ} \mathrm{C}$ for the reference $\mathrm{CO}_{2} \mathrm{HP}$, and an inlet water temperature to the evaporator of $20^{\circ} \mathrm{C}$ for the propane $\mathrm{HP}$. The catalogue data of the reference $\mathrm{CO}_{2} \mathrm{HP}$ gives the heating COP including the consumption of auxiliaries such as the fan, hence, the consumption of water pumps has been included in the propane cycle. As seen in Figure 4, the SMCL design gives a slightly higher COP for $\mathrm{T}_{\mathrm{w}, \mathrm{ci}} 30^{\circ} \mathrm{C}$ and $50^{\circ} \mathrm{C}$, but this difference is now slightly higher due to the inclusion of the water pump consumption, which is higher at the subcooler than at the condenser. When the SMS system is compared with the reference $\mathrm{CO}_{2} \mathrm{HP}$, the propane cycle working with subcooling has about a 5\% to $14 \%$ higher $\mathrm{COP}$ than the commercial reference $\mathrm{CO}_{2} \mathrm{HP}$ based on the catalogue data. There is no data for the reference $\mathrm{CO}_{2} \mathrm{HP}$ with water inlet temperatures higher than $24^{\circ} \mathrm{C}$, but the trend 
of the available results indicates that the difference between the propane and the $\mathrm{CO}_{2}$ heat pumps would be greater than $14 \%$ at higher $\mathrm{T}_{\mathrm{w}, \mathrm{c} \text {. }}$

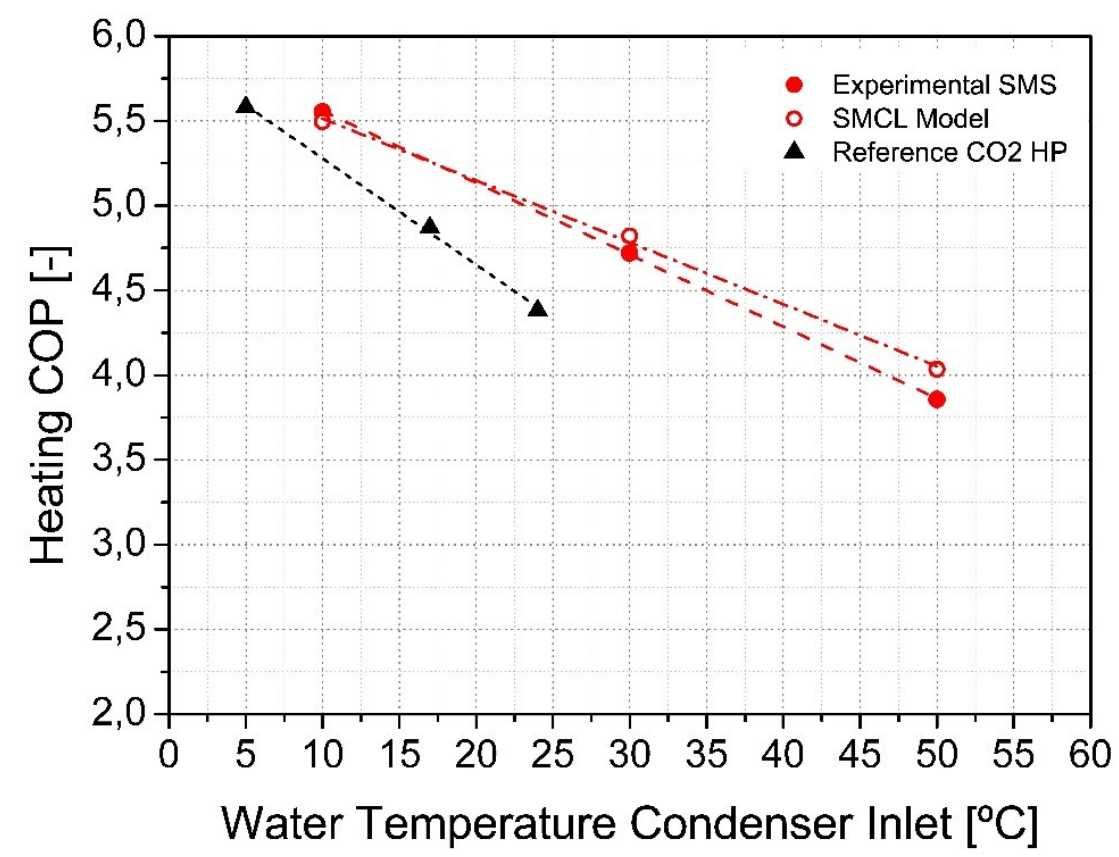

Figure 9: Heating COP as a function of $\mathrm{T}_{\mathrm{w}, \mathrm{c} \text {. }}$ Comparison: $\mathrm{SMS}$ experimental, SMCL model and the reference commercial $\mathrm{CO}_{2} \mathrm{HP}\left(\mathrm{T}_{\mathrm{w}, \mathrm{co}}=60^{\circ} \mathrm{C}\right)$.

One of the characteristics of the reference $\mathrm{CO}_{2} \mathrm{HP}$ is the ability to warm water up to $90^{\circ} \mathrm{C}$ without the requirement of an electric heater. In order to evaluate the capabilities of the propane system to produce water in that temperature range, an experimental test campaign of the prototype SMS was developed. Figure 10 shows the heating COP comparison between the obtained experimental data of the SMS design, the SMCL model and reference $\mathrm{CO}_{2} \mathrm{HP}$, at different water production temperatures, from $60^{\circ} \mathrm{C}$ to $90^{\circ} \mathrm{C}$. The inlet water temperature to the condenser was fixed to $30^{\circ} \mathrm{C}$, while the inlet water temperature at the gas cooler is $24^{\circ} \mathrm{C}$ (the closest to the catalogue data). Both propane cycles have a similar heating COP, although the COP penalty with the water temperature is slightly higher for the SMCL. The propane cycle has a COP about $20 \%$ higher than the commercial $\mathrm{CO}_{2}$ cycle when the hot water is produced at $90^{\circ} \mathrm{C}$.

Table 4 shows some parameter results for the SMS cycle. The refrigerant discharge temperature of the propane cycle producing hot water at $90^{\circ} \mathrm{C}$ is $111^{\circ} \mathrm{C}$, which is lower than the maximum working discharge temperature recommended from the compressor manufacturer $\left(130^{\circ} \mathrm{C}\right)$. The condensing temperature is $78.9^{\circ} \mathrm{C}$. 


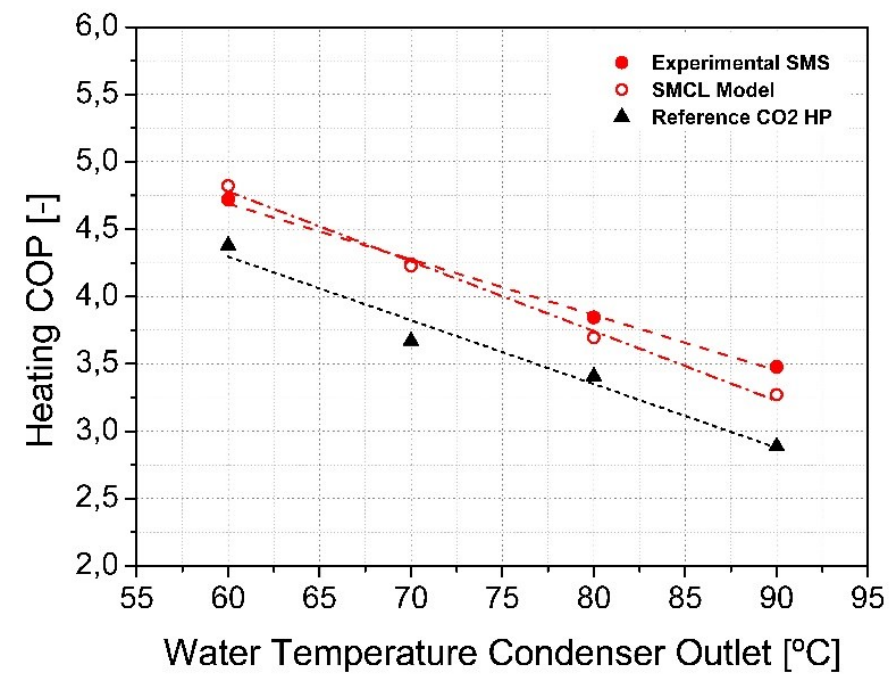

Figure 10: Heating COP as a function of $\mathrm{T}_{\mathrm{w}, \mathrm{co}}$. Comparison: $\mathrm{SMS}$ experimental, SMCL model and the commercial $\mathrm{CO}_{2} \mathrm{HP}\left(\mathrm{T}_{\mathrm{w}, \mathrm{c} i}=30^{\circ} \mathrm{C}\right)$.

\begin{tabular}{|c|c|c|c|c|}
\hline & $\begin{array}{c}T_{w, c o}= \\
60 \circ C\end{array}$ & $\begin{array}{l}T_{w, c o}= \\
70=C\end{array}$ & $\begin{array}{c}T_{w, c o}= \\
80 \cong \mathrm{C}\end{array}$ & $\begin{array}{l}T_{w, c o}= \\
90=C\end{array}$ \\
\hline $\mathrm{COP}_{\mathrm{h}}$ & 4.72 & 4.24 & 3.84 & 3.48 \\
\hline $\mathrm{T}_{\text {cond }}[\stackrel{\circ}{ } \mathrm{C}]$ & 56.7 & 64.5 & 71.9 & 78.9 \\
\hline $\mathbf{T}_{\text {disch }}[\mathbf{o} \mathbf{C}]$ & 81 & 90 & 100 & 111 \\
\hline
\end{tabular}

Table 4: Results for different water temperature production. SMS experimental with $\mathrm{T}_{\mathrm{w}, \mathrm{c} i}=30^{\circ} \mathrm{C}$.

\section{CONCLUSIONS}

This paper presents a comparison between the different HP designs to produce SHW using natural refrigerants.

The study includes two subcritical systems designed specifically to work at high water temperature lift and $\mathrm{CO}_{2}$ systems.

Regarding the comparison of the two different subcritical heat pump configurations, the main conclusions are:

- The SMCL system is able to optimise the heat exchanger area in a better way.

- The SMCL has shown a significant reduction of the COP working at high subcooling and high evaporating temperatures.

- SMLC has one less heat exchanger, but an additional electronic valve and a more sophisticated control algorithm than the SMS system. In order to choose between both systems, cost criteria should be the most important factor. From the point of view of energy efficiency, both systems have shown very competitive and close COP with only minor differences for some specific working conditions. 
- The effect of the sizing of the condenser of the SMLC configuration has been analysed. The obtained results have shown that in order to be able to reach the higher COPs obtained in this work, dimensioning the condenser properly is critical.

Comparing these two systems with $\mathrm{CO}_{2}$ systems available on the market:

- Propane subcritical systems have shown a higher COP (between $5 \%$ and $20 \%$, depending on the water temperature lift).

- Propane subcritical system is able to heat water from $30^{\circ} \mathrm{C}$ to $90^{\circ} \mathrm{C}$ with an improvement of up to $11 \%$ in COP compared to $\mathrm{CO}_{2}$ systems.

The obtained results show that the proposed systems constitute very efficient solutions that could increase the efficiency of the systems available for the production of sanitary hot water. In addition, it has been demonstrated that the proposed designs could be used in an efficient way in a broader range of applications that require higher water temperatures, such as old boilers used in some parts of Europe, which require water at $80^{\circ} \mathrm{C}$ or industrial cleaning processes requiring water at a high temperature.

\section{Acknowledgements}

This work has been developed in the Seventh Framework Program of the European Union by the project, Next Generation of Heat Pump Technologies (NEXTGHP), grant agreement 307169. The authors thank the support given. Part of the work presented was carried by Miquel Pitarch-Mocholí with the financial support of a PhD scholarship from the Universitat Politècnica de València. The authors would like also to acknowledge the Spanish 'MINISTERIO DE ECONOMIA Y COMPETITIVIDAD', through the project ref-ENE2014-53311C2-1-P-AR "Aprovechamiento del calor residual a baja temperatura mediante bombas de calor para la produccion de agua caliente" for the given support.

\section{REFERENCES}

[1] Blarke MB. Towards an intermittency-friendly energy system: Comparing electric boilers and heat pumps in distributed cogeneration. Appl Energy 2010; 91(1): 349-65.

[2] European Directive 2009/28/EC of The European Parliament and of The Council. eur-lex.europa.eu

[3] Ozone Secretariat. "The Montreal protocol on substances that deplete the ozone layer." United Nations Environment Programme, Nairobi, Kenya, 2000. 
[4] EU 'F-Gas' Regulation 517/2014, 2014. Regulation (Eu) No. 517/2014 of the European Parliament and of the Council of 16 April 2014 on fluorinated greenhouse gases and repealing Regulation (EC) No. 842/2006.

[5] Lorentzen G. The use of natural refrigerants: a complete solution to the CFC/HCFC predicament. Int J Refrig 1995; 18(3): 190-7.

[6] ECO-CUTE project, http://www.r744.com/assets/link/enEX_ecocute.pdf (accessed: 05-02-2015).

[7] Rieberer R, Kasper G, Halozan J. $\mathrm{CO}_{2}$-a Chance for once through Heat Pump Heaters, $\mathrm{CO}_{2}$ Technology in Refrigeration, Heat Pumps and Air Conditioning Systems. IEA Heat Pump Centre, Trondheim, Norway, 1997.

[8] Nekså P, Rekstad H, Zakeri GR, Schiefloe PA. CO2-heat pump water heater: characteristics, system design and experimental results. Int J Refrig 1998; 21(3): 172-9.

[9] Nekså P. $\mathrm{CO}_{2}$ heat pump systems. Int J Refrigeration 2002; 25(4): 421-7.

[10] Cecchinato L, Corradi M, Fornasieri E, Zamboni L. Carbon dioxide as refrigerant for tap water heat pumps: a comparison with the traditional solution. Int J Refrig 2005; 28(8): 1250-8.

[11] Pitarch M, Navarro-Peris E, Gonzálvez-Maciá J, Montagud C, Corberan JM. Influence of Water Lift Temperature in Transcritical and Subcritical Refrigerants. In: VII Congreso Ibérico de Ciencias y Técnicas del Frío, Tarragona, Spain, 2014.

[12] Kauf F. Determination of the optimum high pressure for transcritical $\mathrm{CO}_{2}$-refrigeration cycles. Int J Therm Sciences 1999; 38(4): 325-30.

[13] Chen $\mathrm{Y}, \mathrm{Gu}$ J. The optimum high pressure for $\mathrm{CO}_{2}$ transcritical refrigeration systems with internal heat exchangers. Int J Refrig 2005; 28(8): 1238-49.

[14] Sarkar J, Bhattacharyya S, Ram Gopal M. Optimization of a transcritical $\mathrm{CO}_{2}$ heat pump cycle for simultaneous cooling and heating applications. Int J Refrig 2004; 27: 830-8.

[15] Chaichana C, Ayea L, Chartersb WWS. Natural working fluids for solar-boosted heat pumps. Int J Refrig 2003; 26: 637-43.

[16] Eriksson M, Lennart V. Future use of heat pumps in Swedish district heating systems: Short-and longterm impact of policy instruments and planned investments. Appl Energy 2007; 84(12): 1240-57.

[17] Quantum, Commercial heat pump for SHW production: http://quantumenergy.com.au/ (accessed: 15-112016).

[18] Justo Alonso M, Stene J. IEA Heat Pump Programme Annex 32. Umbrella Report, System Solutions, Design Guidelines. Prototype System and Field Testing, 2010.

[19] Fernando P, Palm B, Lundqvist P, Granryd E. Propane heat pump with low refrigerant charge: design and laboratory tests. Int J Refrig 2004; 27: 761-73.

[20] Corberán JM, Martínez-Galván I, Gonzálvez-Maciá J. Charge optimization study of a reversible waterto-water propane heat pump. Int J Refrig 2008; 31: 716-26.

[21] Corberán JM, Martínez-Galván I, Martínez-Ballester S, Gonzálvez-Maciá J, Royo-Pastor R. Influence of the source and sink temperatures on the optimal refrigerant charge of a water-to-water heat pump. Int J Refrig 2011; 34: 881-92. 
[22] Guo JJ, Wu JY, Wang RZ, Li S. Experimental research and operation optimization of an air-source heat pump water heater. Appl Energy 2011; 88: 4128-38.

[23] Li H, Yang H. Study on performance of solar assisted air source heat pump systems for hot water production in Hong Kong. Appl Energy 2010; 87: 2818-25.

[24] Choi JM, Kim YC. Influence of the expansion device on the performance of a heat pump using R407C under a range of charging conditions. Int J Refrig 2004; 27: 378-84.

[25] Redón A, Navarro-Peris E, Pitarch M, Gonzálvez-Macia J, Corberán JM. Analysis and optimization of subcritical two-stage vapor injection heat pump systems. Appl Energy 2014; 124: 231-40.

[26] Lihan X. Potential of controlling subcooling in residential Air conditioning system. Master's thesis, University of Illinois at Urbana-Champaign, 2014.

[27] Next Generation of Heat Pumps working with Natural fluids. FP7-ENERGY project. Website of the project: http://www.nxthpg.eu/. (accessed: 20-11-2016).

[28] Tammaro M, Montagud C, Corberán JM, Mauro AW, Mastrullo R. A propane water-to-water heat pump booster for sanitary hot water production: Seasonal performance analysis of a new solution optimizing COP. Int J Refrig 2015; 51: 59-69.

[29] Pitarch M, Navarro-Peris E, Gonzálvez-Maciá J. Corberan JM. Experimental study of a subcritical heat pump booster for sanitary hot water production using a subcooler in order to enhance the efficiency of the system with a natural refrigerant (R290). Int J Refrig 2017; 73: 226-34. Doi: 10.1016/j.ijrefrig.2016.08.017.

[30] Gong G, Zeng W, Wang L, Wu C. A new heat recovery technique for air-conditioning/heat-pump system. Appl Therm Eng 2008; 28: 2360-70.

[31] Pitarch M, Navarro-Peris E, Gonzálvez-Maciá J. Corberan JM. Experimental study of a heat pump with high subcooling in the condenser for sanitary hot water production. Science Technol for the Built Environ, 'Under revision'

[32] IMST-ART: Simulation tool to assist the selection, design and optimization of refrigerator (v3.70), http://www.imstart.com (accessed: 07-07-2016).

[33] Q-ton Catalogue data ESA30E-25, Commercial use Heat pump water heater Q-ton catalogue data ESA30E-25, Mitsubishi Heavy Industries.

[34] Corberán JM, Gonzálvez J, Montes P, Blasco R. 'ART' A Computer Code to Assist the Design of Refrigeration and $\mathrm{A} / \mathrm{C}$ Equipment. In: International Refrigeration and Air Conditioning Conference (Purdue University). Paper 570, 2002. 


\section{LIST OF FIGURES}

Figure 1: Heat Pump subcooler in series with condenser; a) scheme, b) P-h diagram.

Figure 2: Heat Pump subcooling controlled by a throttling valve; a) scheme, b) P-h diagram.

Figure 3: Model validation; a) heating COP, b) condensing pressure.

Figure 4: Results for two condenser height; a) heating COP, b) condensing pressure.

Figure 5: $\%$ of area dedicated for subcooling as a function of subcooling and $\mathrm{T}_{\mathrm{w}, \mathrm{ci}}$ (SMCL and the fixed area for SMS).

Figure 6: a) Heating COP and b) condensing pressure as a function of subcooling and condenser size $\left(\mathrm{T}_{\mathrm{w}, \mathrm{ci}}=30^{\circ} \mathrm{C}\right)$.

Figure 7: a) Condenser dedicated area as a function of condenser size, b) refrigerant and water temperature profile in the condenser $\left(\mathrm{T}_{\mathrm{w}, \mathrm{ci}}=30^{\circ} \mathrm{C}\right)$.

Figure 8: Heating COP as a function of subcooling for $\mathrm{T}_{\mathrm{w}, \mathrm{ei}}=30^{\circ} \mathrm{C}$ and $\mathrm{T}_{\mathrm{w}, \mathrm{ci}}=10^{\circ} \mathrm{C}$

Figure 9: Heating COP as a function of $\mathrm{T}_{\mathrm{w}, \mathrm{ci}}$. Comparison: SMS experimental, SMCL model and the reference commercial $\mathrm{CO}_{2} \mathrm{HP}\left(\mathrm{T}_{\mathrm{w}, \mathrm{co}}=60^{\circ} \mathrm{C}\right)$.

Figure 10: Heating COP as a function of $\mathrm{T}_{\mathrm{w}, \mathrm{co}}$. Comparison: SMS experimental, SMCL model and the commercial $\mathrm{CO}_{2} \mathrm{HP}\left(\mathrm{T}_{\mathrm{w}, \mathrm{ci}}=30^{\circ} \mathrm{C}\right)$. 